ICAMS $2020-8^{\text {th }}$ International Conference on Advanced Materials and Systems

\title{
INNOVATIVE ECOLOGICAL PROCESSES WITH RECOVERY OF CHEMICALS AND WATER FOR REUSE IN LEATHER SECTOR - AN ECONOMICAL AND SUSTAINABLE APPROACH
}

\author{
SENGODA GOUNDER RAJAMANI
}

Chairman, Asian International Union of Environment Commission (AIUE), No.18/45, South Beach Avenue, MRC Nagar, Chennai - 600 028, India, Mobile: + 91 - 98400 63210. E-mail: dr.s.rajamani@gmail.com

\begin{abstract}
The effluent discharged from conventional process in textile dyeing and tanneries are unable to meet some of the discharge parameters such as Total Dissolved Solids (TDS) in the existing physiochemical \& biological treatment units. In addition to TDS management the control of volatile solids in hazardous category sludge is also becoming a necessity. To overcome these challenges faced by tanneries in the world leather, improved cleaner production, segregation of saline soak liquor and separate treatment, modified chrome recovery system and recovery of chromium \& sodium chloride salt in the form of powder and quality water with TDS less than $500 \mathrm{mg} / \mathrm{l}$ for reuse by tanneries have been developed for field application. Physiochemical treatment is converted into total biological treatment with sulphide oxidation using enzyme and biomass which resulted in 50\% reduction in sludge generation. The secondary treated effluent and supernatant from chrome recovery system are processed with membrane units for recovery of high saline stream and quality salt for reuse in pickling process and other industrial requirement. These developments are being implemented at field level for cluster of nearly 400 tanneries in India which is first of its kind in the world.
\end{abstract}

Keywords: Cleaner production, Water \& Chrome recovery, TDS control

\section{INTRODUCTION}

The tanneries in World Leather Sector process about 17 million tones of hides \& skins per year. Only less than $20 \%$ of fresh hides and skins are processed without applying salt and more than 8-10million tones of salt mainly in the form of sodium chloride is applied for curing. They are transported, stored and processed in a period of 2-6 months. The entire salt applied is discharged as waste in the effluent as dissolved solids, causes environmental challenges due to increase in salinity, depletion of quality water resources and transfer of non-degradable pollutants such as salt from one region to other region in the world.

With a view address the environmental challenges, technological developments such as (i) Advanced process control and cleaner production, (ii) Segregation of Spent chrome stream and adoption of improved chrome recovery system by recovering chromium in the form of cake and power, (iii) Segregation of saline stream with high TDS around 20000-30000mg/L from soak liquor, separate treatment and recovery of quality salt and water for reuse by adopting ZLD system, (iv) Improved biological treatment system with mild chemical usage for reduced sludge generation, (iv) Advanced tertiary treatment system for the application of Reverse Osmosis (RO) system for recovery of water. Recent applied $R \& D$ on the sustainable development in cleaner leather production, environmental protection techniques with focus on saving of energy and chemical by converting the physiochemical treatment into total biological treatment, water-recovery for reuse, quality salt recovery for reuse, etc. are explained in this paper. 
Innovative Ecological Processes with Recovery of Chemicals and Water for Reuse in Leather Sector - An Economical and Sustainable Approach

\section{SEPARATE TREAMTENT OF SOAK STREAM FOR RECOVERY OF QUALITY SALT AND WATER}

Due to inherent quality of industrial wastewater such as textile dyeing units, tanneries etc., the conventional treatment plants are unable to meet the prescribed TDS level of 2100 $\mathrm{mg} / \mathrm{l}$ in the treated effluent. In addition to TDS management the control of volatile solids in hazardous category sludge is also becoming a necessity. For control of salinity, sludge and viable management of TDS with recovery of quality water and salt from wastewater, the required treatment steps are (i) Cleaner production and other viable process control in tanneries, (ii) Segregation of saline soak liquor, spent chrome liquor for separate treatment, (iii) Improved two stage biological treatment systems with better efficiency in BOD and COD removal, (iv) Minimum usage of chemicals in the treatment process and reduction in sludge generation, (v) Reduction in TDS level in the mixed stream and (vi) Tertiary treatment of the low saline mixed stream and integration of treated tannery effluent with treated domestic sewage wherever feasible for TDS management.

The availability of domestic sewage is limited in many locations for dilution/mixing with treated tannery effluent for TDS management. The viable plan of segregation of soak liquor, separate treatment and recovery of quality salt will be helpful in reduce the TDS level in the mixed stream and scope for adoption of dilution / mixing with available treated domestic sewage.

The segregated soak liquor generated from presoaking and main soaking is taken to the CETPs through separate pipe line and after primary and secondary treatment units, membrane system is adopted for recovery of water and quality of saline stream for reuse in pickling. The balance treated saline stream is evaporated in the multiple effect evaporator and quality salt ( $98 \%$ purity) is recovered for reuse without any difficulty. In addition to recovery and reuse of quality water by the industry, the additional benefits are savings in chemical usage in the tanning process and reduction in pollution load in the effluent.

The segregated chrome stream is taken for Centralized Chrome Recovery System (CCRS) for recovery of chromium in the form of chromium cake. In the improved chrome recovery system, the time required in the chrome recovery process is reduced from $16 \mathrm{hrs}$ to less than $8 \mathrm{hrs}$. By avoiding the soak stream and supernatant from the CCRS to the main composite stream, the TDS level will be reduced from the level of about $15000 \mathrm{mg} / \mathrm{l}$ to $8000 \mathrm{mg} / \mathrm{l}$.

\section{IMPROVED COMMON CHORME RECOVERY SYSTEM}

The basic concept, design and development of improved Common Chrome Recovery System (CCRS) comprises of the following:

- Segregation of spent chrome liquor and collection in separate tank, transportation through tankers mounted on trucks with GPS and vacuum pumps

- Separate collection tanks with screen chamber near CCRS for discharge of spent chrome liquor from the tankers

- Transfer of spent chrome liquor from the collection tank by pumping to the main reactor for chrome precipitation by using suitable Alkali chemical dosing

- Decanting of supernatant, clarification and distribute in tanneries for pickling with alternative option of recovery of water using UF\&RO units installed for saline soak treatment system and recovery of reusable salt using the MEE system

https://doi.org/10.24264/icams-2020.III.15 
ICAMS $2020-8^{\text {th }}$ International Conference on Advanced Materials and Systems

- Dewatering of Chromium Hydroxide slurry and making it in the form of cake and powder. Further process of making chromium cake/powder in to Basic Chromium Sulphate (BCS) for reuse in tanneries.

The process flow diagram of segregation and collection of three streams viz. (i) Saline Soak liquor, (ii) Spent Chrome liquor and (ii) Composite stream with low TDS and separate treatment is shown below:

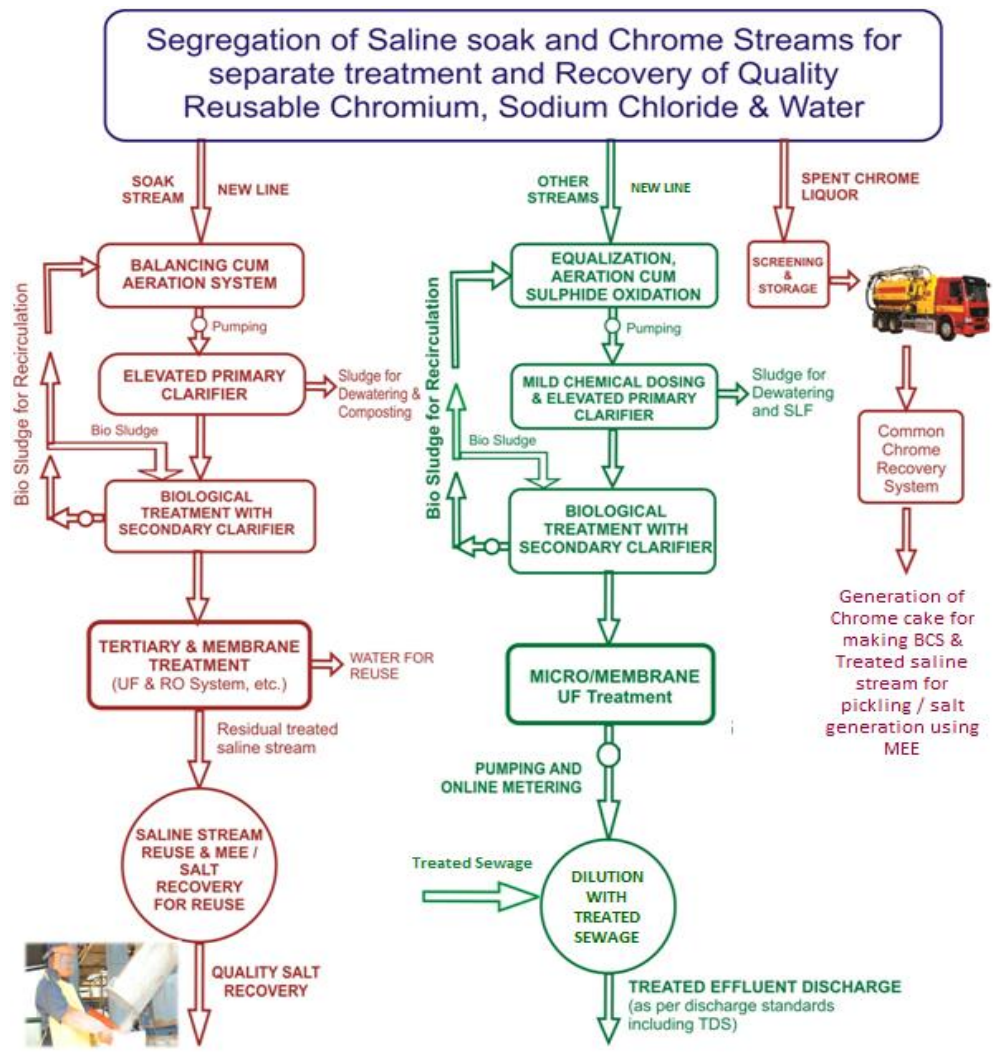

Figure 1. Treatment process of Soak saline, Spent chrome and Composite low saline streams

\section{Chrome Precipitation in Main Reactor Using Suitable Alkali Chemical}

The equalized spent chrome liquor from the collection tank is pumped to the Reaction tank, provided with a slow speed agitator. The alkali solution shall be prepared in the Alkali preparation tank by mixing alkali and water. The Alkali dosing feed pump shall draw the Alkali solution from the alkali preparation tank to the Reaction tank.

The alkali dosage is regulated by the $\mathrm{pH}$ analyzer/transmitter with integrated controller installed in the Reaction tank. Depending on the $\mathrm{pH}$ value in the reaction tank the Alkali solution feed pump speed will be varied to control the reaction. The agitator in the Reaction tank will ensure the proper mixing of the spent chrome liquor and the alkali solution. The chromium present in the chrome liquor will be quantitatively precipitated as chromium hydroxide by increasing the $\mathrm{pH}$.

The Chemical reaction of a typical chrome recovery process is:

https://doi.org/10.24264/icams-2020.III.15 
Innovative Ecological Processes with Recovery of Chemicals and Water for Reuse in Leather Sector - An Economical and Sustainable Approach

$\mathrm{Cr} 2(\mathrm{SO} 4) 3+6 \mathrm{NaOH} \rightarrow 2 \mathrm{Cr}(\mathrm{OH}) 3+3 \mathrm{Na} 2 \mathrm{SO} 4$

\section{Separation of Chrome Slurry and Supernatant from the Main Reactor}

In about 3-4 hours the chromium precipitates and settles as chromium hydroxide slurry in the bottom of the main reactor. The supernatants account for about 70 to $80 \%$ of the volume in the Reaction tank. After settling the chrome slurry has to be separated from supernatant by decanting the supernatant by providing proper arrangement. Chrome slurry from the bottom of the reaction tank shall be discharged by gravity into the collection tank in the form of chromium hydroxide.

\section{Dewatering of Chromium Hydroxide Slurry \& Making it in the Form of Cake}

A series of Filter press with feed tank shall be provided to dewater the chromium hydroxide slurry and convert into chromium hydroxide cake. The solid concentration of the chromium hydroxide cake shall be about $30 \%$. An agitator shall be provided in the each of the filter press feed tank for proper feed in to the filter press. The Filter press feed pump shall draw the chrome hydroxide precipitate from the filter press feed tank and pump it to the filter press. The water passes through the filter clothes and chromium hydroxide is retained. This shall be repeated till the filtration cycle is completed. The filtrate is collected in the supernatant collection tank and then taken for further process and reuse.

At the end of the filtration cycle, the filter press is opened and chromium hydroxide cake is collected in a separate tray, shifted to storage yard to be provided adjacent to CCRS and kept for further dry and stored in anticorrosive polythene bags. The chromium hydroxide cake is further processed by authorized vendors / BCS manufacturers and reused in the member industries for recycle.

The overall schematic diagram of the improved chrome recovery system is given below:

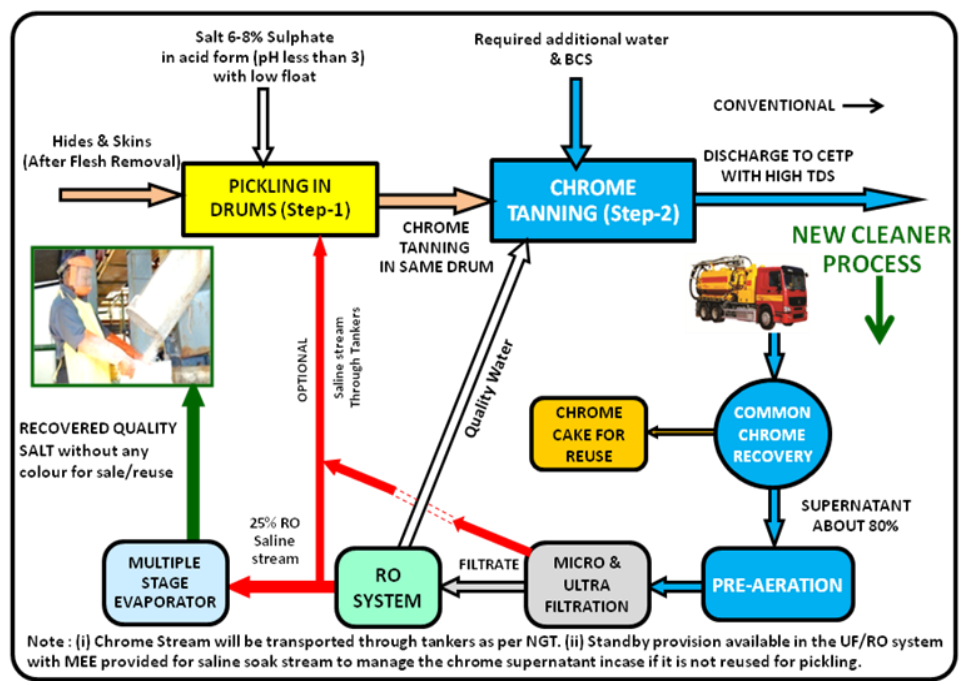

Figure 2. Chrome Stream Treatment, Recovery \& Reuse 
ICAMS $2020-8^{\text {th }}$ International Conference on Advanced Materials and Systems

Integration of Equalization cum Mixing System with Biological Treatment for Sulphide Oxidation

The effluent is collected in equalization cum mixing system, pumped to the primary clarifier, mixed with high dosing of chemicals such as lime alum, etc. The conventional system adopted in most of the CETPs in India could not reduce the sulphide level in the physiochemical treatment and the sludge accumulation in the equalization tank is one of the major problems. The COD reduction to the prescribed level (i.e. 250mg/l) in the final treated effluent could not be met by some of the CETPs adopting conventional physiochemical and biological treatment. The performances of the aerobic biological treatment system with limited detention time are not satisfactory and unable to produce required quality effluent.

With a view to oxidize the sulphide present in the effluent, control the sludge settling in the equalization tank and to minimize the chemical usage the equalization system has been upgraded with increased detention time, increased depth and usage of new type of aspirators integrated with compressor. The residual excess biosludge from secondary clarifier is pumped to the equalization tank which is helpful in biological oxidation process and to reduce the chemical dosage in the first stage clarifier.

The primary clarifier units are also upgraded by providing elevated clarifiers with minimum required chemical dosing. This improved system is performing better in terms of sludge settling, withdrawal and dewatering.

The improved aeration system with jet aspirator has been successfully adopted in many CETPs in Tamilnadu and proposed to be implemented in more CETPs. The sustainable alternatives to total ZLD system for single combined stream have been developed and are being introduced in upgradation of CETPs in Uttar Pradesh and other States. It is also estimated that nearly $80 \%$ capacity of the wastewater from Indian Leather Sector will be treated by adopting cleaner technologies, segregation of streams and separate treatment, integration with treated domestic sewage, etc. In this circumstance for long term sustainability of the CETPs which adopted ZLD for single combined streams, the concept of separate treatment of saline streams with recovery of quality reusable salt, cleaner productions, etc. may have to be followed. UNIDO in its recent technical publications on environment and effluent treatment for World Leather sector clarifies the limitations of ZLD system and emphasize the segregated stream treatment aspects.

\section{CONCLUSION}

The conventional effluent treatment systems are being upgraded by segregating the saline soak stream with separate treatment, adoption of UF \& RO and Multiple Effect Evaporators (MEE) with recovery of quality salt for reuse. About $200 \mathrm{~kg}$ of quality salt (sodium chloride) is recovered from the effluent discharged during the process of each $\&$ every tone of hides \& skins. The physiochemical treatment is converted into total biological treatment system to reduce sludge generation by $50 \%$, achieving the pollution control discharge standards and clarity in treated effluent. Upgradation of CETPs with Improved Cleaner Production Process, Centralized Chrome Recovery and Reuse systems, integrated treatment with treated domestic sewage for sustainable TDS management with financial support from National and International organization in India and other countries. These technological developments and upgradation of CETPs

https://doi.org/10.24264/icams-2020.III.15 
Innovative Ecological Processes with Recovery of Chemicals and Water for Reuse in Leather Sector - An Economical and Sustainable Approach

are being implemented in many locations covering more than 700 tanneries in India with financial outlay of more than 150 million US dollars.

\section{Acknowledgements}

Contributions of National Mission for Clean Ganga (NMCG), Department for Promotion of Industry and Internal Trade (DPIIT), National Green Tribunal (NGT), Banthar Industrial Pollution Control Company (BIPCC), Unnao Tanneries Pollution Control Company (UTPCC), IL\&FS Cluster Development Company, Asian International Union Environment (AIUE) Commission, Asian International Forum and others commission members from various countries, IULTCS, UNIDO, European Union including Italy, Spain, Netherlands and other Countries such as China, Romania, Turkey and Russian Federation, New Zealand are acknowledged. Leather Industry Associations and Common Effluent Treatment Plants (CETP) specifically Pallavaram, Dindigul, Madhavaram, Jajmau CETPs in India are acknowledged.

\section{REFERENCES}

Rajamani, S. (2015), "Novel Industrial Wastewater Treatment Integrated with Recovery of Water and Salt under Zero Liquid Discharge Concept", The Pacific Basin Consortium for Environment and Health, University of Indonesia, City of Depok, West Java, https://doi.org/10.1515/reveh-2016-0006.

Rajamani, S. (2016), "Innovative Environmental Technologies including Water Recovery for Reuse from Tannery and Industrial Wastewater - Indian and Asian Scenario", Proceedings of the 6th International Conference on Advanced Materials and Systems (ICAMS 2016), Bucharest, Romania, https://doi.org/10.24264/icams-2016.IV.13.

Rajamani, S. (2018), "Sustainable Environmental Technologies Integrated with Cleaner Production - Recent developments in World Leather Sector", XIVth International Scientific-Practical Conference, Ulan-Ude, Russia.

Rajamani, S. (2018), "Viable Environmental Technologies integrated with Cleaner Production - Sustainable Options for Global Leather Sector", Innovative solutions for sustainable development of textile and leather industry - International Science Conference 2018, Oradea, Romania

Rajamani, S. (2019), "Innovative Technologies on Cleaner Production and Waste Management in Tanneries", International Leather Engineering Congress Innovative Aspects for Leather Industry, Izmir, Turkey.

Rajamani, S. (2020), "Sustainable ZLD System by Adopting Centralized Treatment of Segregated Streams for Recovery of Reusable Quality Chemical, Salt \& Water - First of its kind in India \& Asia”, Leather News India Journal. 